\title{
FATIGUE LIFE ESTIMATION OF 6061 ALUMINIUM ALLOY BASED ON MODAL DAMPING MEASUREMENTS
}

\author{
S.A. Asseala and F.R. Gomaa \\ Faculty of Engineering Shebin El-Kom, Minoufiya University, Egypt \\ E-mail: salahassela@yahoo.com
}

\begin{abstract}
The damping property of 6061 aluminium alloys, fabricated by hot isostatic pressing (HIP), has been studied for different ratios of fatigue on the base of modal damping analysis. The effects of age hardening on hardness, fatigue strength and damping loss factor of the material are discussed. On the other hand, the interrelations of fatigue life ratios and the damping loss factor are examined using modal analysis of free-free standard fatigue specimens within a wide range of resonance frequencies $(2000 \mathrm{~Hz}-25 \mathrm{kHz})$. Methodologies used to generate data and extract the characteristics of damping phenomenon have been illustrated. Numerical analysis of values of damping loss factor has been evaluated and compared with experimental measurements.

A rotating bending fatigue test is performed to correlate the modal damping to fatigue damage. The results show that, age hardening process increases the fatigue strength by $15 \%$ and the damping loss factor by $160 \%$. The underlying mechanisms are analyzed and discussed. The results seem to be a useful guide that may help in estimating the lifetime or at least the remaining life of a member loaded under fatigue through measuring damping loss factor.

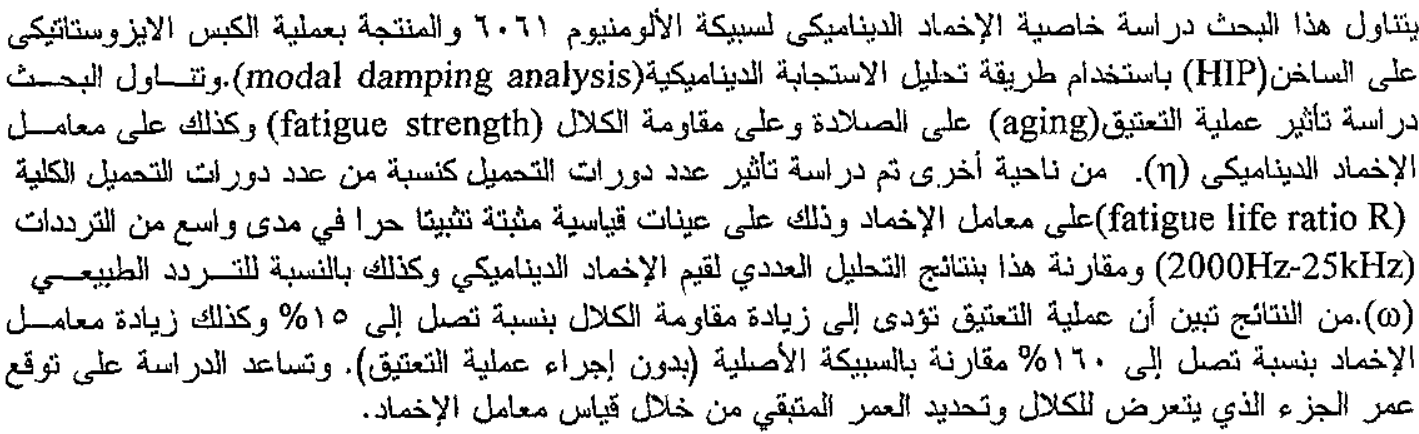

Keywords: Modal Testing -Fatigue-Aging-Dislocation-6061Aluminum Alloy-Modal Damping

\section{1- INTRODUCTION}

Lightweight systems, in which aluminums alloys are involved, are becoming more and more important in mechanical engineering such as robotics, machinetools and automotive industry. However, a major problem arises from the mechanical vibrations, which may be noxious as it concerns machine tool precision, fatigue of components or simply noise pollution. There is then a need to increase the damping capacity of the light alloys which are used in mechanical dynamical environment engineering and which are submitted to a severe dynamical environment.

Fatigue is an important parameter to be considered in the behavior of mechanical components subjected to constant and variable amplitude loading. Mechanical, metallurgical and environmental variables can influence the fatigue resistance of a structural component. Fatigue is the primary cause for $80-90 \%$ of all engineering failures [1].

The research trends on damping mechanism of aluminum alloy that have been conducted so far could be divided into two main categories, i.e. the dislocation damping and interfacial damping mechanism [2]. Since the interfacial damping is intimately concerned with the absorbing ability of interface and grain boundary to the thermal gradient or mechanical strain formed in internal structure, it has been frequently proposed as dominant mechanism on metal matrix composite (MMC) and rapid solidification and powder metallurgy (RS-PM) [3].

Liet.al. [2-3] have reported in their experimental research that the damping capacity of RS-PM Al-based 
alloy is enhanced through microstructure change by precipitation of hard dispersion. Thus, if the microstructure transformation is accomplished, so that it's favorable to dislocation damping behavior, this simultaneous enhancement of mechanical property and damping capacity will be remarkably achieved even in conventional alloy systems.

The effect of microstructure change on the fatigue behavior and dynamic (Modal) characteristics of austempered ductile iron has been investigated [4].The effect of microstructure change on dynamic behavior was investigated with the objective of exploiting the ability of modal testing to predict the microstructure.

It was found that the damping ratio was the most noticeable response to the change in material and fatigue life [5].Based on these observations, it appears promising to develop a method which is capable of relating modal damping deviations to structural fatigue at failure mode of structure.

Aging conditions significantly affects the resonant vibration, such as vibration deformation feature and damping capacity, in the case of precipitation hardened Al-Mg-Si alloy. Under the vibration conditions in study by J.M.Song et al. [6], the damping capacity decreases with a longer artificial aging time, but this tendency reverses when over-aging conditions are reached.

The problem of surveying the integrity of industrial structure becomes an increasingly important issue as the operational safety requirements turn to be more stringent and maintenance cost need to be reduced. This requires advanced safety inspection techniques to account for the nature of damages. With this setting any concept for detecting and localizing structure damage from vibration data must be capable of working with information from a small number of generally inappropriately placed excitation points and response sensors. This leads to the introduction of experimental modal analysis, as a nondestructive tool. Deobling et al. [7-8] gave a review of the research on crack and damage detection and location in structure using vibration data. The estimation of crack size and location based on the change in modal parameters was investigated [9]. The use of modal analysis for damage detection in aluminum cylinders was studied by Davis [10]. The most popular approach is where modal analysis is repeatedly performed and changes in the modal parameters interpreted in terms of change in the structure. A complete review of related methods can be found in [11]. Because there are multiple modal parameters required to describe each mode, it is logical to inquire whether the parameters are equally sensitive to the failure mode of the structure. The appropriate parameters to trace these parameters as a function of failure mode may vary depending mainly on the type of structure being considered.

The present paper offers an attempt to correlate the damping behavior of a widely used aluminum alloy with its fatigue properties. An understanding of such damping behavior may help to estimate the lifetime (or even the remaining period) of a member loaded under fatigue through the relation between damping loss factor $(\eta)$ and failure modes. The second aim is to find a good candidate alloy, which can be developed as a new high damping material after precipitation hardening.

\section{2- PROBLEM FORMULATION}

The method proposed is based on the observation that the influence of fatigue life ratio on the structure modal quantities changes from mode to mode. Comparing modal damping values variation before and after fatigue cycles took place; the idea is to solve the inverse problem to set of modal data i.e (modal frequency and modal damping) before and after fatigue cycles to identify the failure mode.

The analytical modal was derived from system matrices to coordinate with the corresponding experimental damping values and the measured frequency response function has been consequently analyzed.

The governing equation of free damping vibration of structure model of $n$ degree of freedom may be expressed as

$\mathrm{mq}^{\prime \prime}+\mathrm{cq} \mathrm{q}^{\prime}+\mathrm{kq}=0$

where, $m, c, k$, are nxn mass damping and stiffness matrices, respectively and $\mathrm{q}$ corresponding $\mathrm{nxl}$ displacement vector. Substituting the trial solution:

$$
\mathrm{q}=\mathrm{V} \mathrm{e}^{* \mathrm{i} \omega t}
$$

The natural frequencies $\omega_{i}$ and the corresponding mode shapes $V_{i}$ for $i=1, \ldots, n$ are obtained by solving the eigenvalue problem. Note that $\mathrm{V}$ is the $\mathrm{nxn}$ orthogonal classical modal matrix formed from the eigen vector $\mathrm{V}_{\mathrm{i}}^{*}$ and the $\Omega$ is the nxn diagonal frequencies $(\omega)_{\mathrm{i}}^{2}$. $V$ and $\Omega$ form the complete set of $n$ eigenpairs.

By using proportional damping approach (Rayliegh) damping.

$$
[c]=\alpha_{\mathrm{m}}[\mathrm{m}]+\beta_{\mathrm{k}}[\mathrm{k}]
$$

where $\alpha$ and $\beta$ are proportionally constant for the $\mathrm{i}^{\text {th }}$ mode. Equation (2) can be split into

$$
C_{i}=\alpha M_{i}+\beta_{k} K_{i}
$$


where, $\mathrm{C}, \mathrm{M}$ and $\mathrm{K}$ are generalized damping, mass and stiffness matrices respectively

$$
\mathrm{i}=1, \mathrm{n}^{*}, \mathrm{n}
$$

where, $i$ is a mode number, $n$ is a number of mode, $n^{*}$ is typical number of damaged modes or failure modes.

The orthogonality properties of mass $m$ and stiffness matrices $\mathrm{k}$ and damping matrices $\mathrm{c}$ are then expressed as

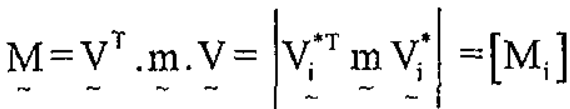

$$
\begin{aligned}
& \mathrm{K}=\mathrm{V}^{\mathrm{T}} \cdot \mathrm{K} \cdot \mathrm{V}=\left|\begin{array}{cc}
\mathrm{V}_{\mathrm{i}}^{* \mathrm{~T}} & \mathrm{~K} \\
\mathrm{~V}_{\mathrm{i}}^{*}
\end{array}\right|=\left[\mathrm{K}_{\mathrm{i}}\right] \\
& \mathrm{C}=\mathrm{V}^{\mathrm{T}} . \underline{\sim} \mathrm{V}=\left|\begin{array}{cc}
\mathrm{V}_{\mathrm{i}}^{* T} & \underset{\sim}{\mathrm{CV}} \mathrm{V}_{\mathrm{i}}^{*}
\end{array}\right|=\left[\mathrm{C}_{\mathrm{i}}\right]
\end{aligned}
$$

where, $M, K, C$, are the nxn diagonal mass stiffness and damping matrices, respectively.

Consequently, equation (1) for the $i^{\text {th }}$ mode is then expressed as,

$$
\mathrm{q}_{\mathrm{i}}^{\prime \prime}+\left(\alpha_{\mathrm{m}}+\beta_{\mathrm{k}} \omega_{\mathrm{i}}^{2}\right) \mathrm{q}_{\mathrm{i}}^{\prime}+\omega_{\mathrm{i}}^{2} \mathrm{q}_{\mathrm{i}}=0
$$

The damping ratio $\zeta_{i}$ and the damping loss factor $\eta_{j}$ for the $i^{\text {th }}$ mode can be then expressed, respectively, as

$$
\begin{aligned}
& 2 \zeta_{\mathrm{i}} \omega_{\mathrm{i}}=\alpha_{\mathrm{m}}+\beta_{\mathrm{k}} \omega_{\mathrm{i}}^{2} \\
& \eta_{\text {ianalytical }}=\alpha_{\mathrm{m}} / \omega_{\mathrm{i}}+\beta_{\mathrm{k}} \omega_{\mathrm{i}}
\end{aligned}
$$

It is obvious that the term $\alpha / \omega_{\mathrm{i}}$ diminishes with increasing frequency. In the case of viscous damping, where $\alpha_{m} / \omega_{i}=0$, the effective damping for particular modes varies directly with the natural frequency of the mode.

\section{2-1. Analytical Modal Damping}

For aluminium light damping material we suppose the damping matrix [c] is proportional to stiffness, mass or to some linear combination of both. Thus instead of $n$ coupled equations we would have $n$ uncoupled and $i^{\text {th }}$ equation will have the form :

$\mathrm{q}_{i}^{\prime \prime}+2 \zeta \omega_{i} \mathrm{q}_{i}^{\prime}+\omega_{i}^{2} \mathrm{q}_{i}=0$

In the case of uniform mass damping, the previous equations can be simplified to be

$\mathrm{C}=\alpha_{\mathrm{m}} \mathrm{m}$

Consequently the equation of motion can be recast as,

$q_{i}^{\prime \prime}+\alpha_{m} q_{i}^{\prime}+\omega_{i}^{2} q_{i}=0$

where

$2 \zeta \omega_{\mathrm{i}}=\alpha_{\mathrm{m}}$ and $\eta_{\mathrm{i}}=\alpha_{\mathrm{m}} / \omega_{\mathrm{i}}$

The proportionality constant $\alpha_{\mathrm{m}}$, is tuned such that $\eta_{\text {ianalytical }}$ provides the best approximation to the measured modal damping values of the structure before the fatigue cycle in a least square sensitivity.
The natural frequencies $\left(\omega_{\mathrm{i}}\right)$ and damping loss factor $\left(\eta_{i}\right)$ are determined numerically by using the general purpose program ANSIS and the results are listed in Table1.

Table 1 Numerical values $\left(\omega_{i}\right)$ and $\left(\eta_{i}\right)$ of free-free specirnen before fatigue test.

\begin{tabular}{|c|c|c|}
\hline \multirow{2}{*}{ Mode No. } & \multicolumn{2}{|c|}{ Theoretical } \\
\cline { 2 - 3 } & $\boldsymbol{\omega}_{\mathrm{i}(\mathrm{HZ})}$ & $\eta_{\mathrm{i}(\%)}$ \\
\hline 1 & 2096 & 0.96 \\
\hline 2 & 4574 & 0.89 \\
\hline 3 & 12601 & 0.72 \\
\hline 4 & 15720 & 0.69 \\
\hline 5 & 20980 & 0.63 \\
\hline 6 & 22030 & 0.58 \\
\hline 7 & 23960 & 0.49 \\
\hline
\end{tabular}

\section{EXPERIMENTAL PROCEDURE}

\section{3-1 Specimen preparation}

The 6061aluminium alloy is selected because of the wide variety of available shapes and processes in which it can be used. It can be easily extruded, forged or cold worked, and offers good strength after heat treatment. Considerable industrial interest exists on aluminium alloys of 6xxx series because of nearly twothird of all extrusions are made from aluminium alloys, and $90 \%$ of these are $6 \mathrm{xxx}$ series alloys. Inert gas atomized aluminium alloy 6061 powders supplied by Valimet Inc., USA, were used to produce all the test materials for this investigation. The powder had an average particle size of $25 \mu \mathrm{m}$, and the composition was found to comply with the supply specification given in Table 2.

Table 2. Nominal chemical composition (wt. \%) of aluminium 6061

$\begin{array}{lllll}\mathrm{Mg} & \mathrm{Si} & \mathrm{Cu} & \mathrm{Cr} & \mathrm{Al}\end{array}$

$\begin{array}{lllll}1.0 & 0.6 & 0.3 & 0.2 & \text { Bal }\end{array}$

Powder metallurgy samples" of aluminium 6061 were produced by HIP technique. Prior to hipping, the compacts were encapsulated and degassed. The HIP conditions were; $\mathrm{T}=520^{\circ} \mathrm{C}, \mathrm{P}=100$ bar and $\mathrm{t}=4 \mathrm{hrs}$ followed by furnace cooling to ambient temperature. Once densification has been achieved, the resulting billets were removed from the encapsulating material and heat treated to the $\mathrm{T} 6$ condition of aluminium alloy (solution treatment $550^{\circ} \mathrm{C}, 2 \mathrm{hrs}$ followed by water quenching then aged at variant temperatures; $150{ }^{\circ} \mathrm{C}$, $175^{\circ} \mathrm{C}$ and $200^{\circ} \mathrm{C}$ for time up to $50 \mathrm{hrs}$ ). The density of the sample was determined on completion of processing and the measured value was compared with the theoretical density of aluminium alloy 6061 material $\left(2.79 \mathrm{~g} / \mathrm{cm}^{3}\right)$ to indicate the level of (volume \%) porosity in the sample. 
The measurements were carried out on the specimens after hipping (as-received), quenched in water and aged at $150^{\circ} \mathrm{C}$ for $18 \mathrm{hrs}$ (peak-aged).

\subsection{Fatigue test:}

The fatigue tests were carried out using a 0ho's Rotary Bending Fatigue Testing Machine (Model H7 Shimadzu Co. Kyoto Japan). Fig.1 shows a schematic drawing of the specimen used in the present work. The tests were carried out at room temperature on the specimens in the as-received, as-quenched, and after peak-aged conditions. The samples were subjected to alternate cycles of tensile and compressive stresses as it is simultaneously bent and rotated.

Tests were terminated by complete fracture of the specimens. At least three specimens were tested to fracture for each data point on S-N curve. The specimens were subjected to different number of cycles $(N)$. The ratio of the number of cycles $(N)$ to the failure number of cycles (Nf) at constant stress $(S=120$ $\mathrm{MPa}$ ) is denoted by

$$
\mathrm{R}=\mathrm{N} / \mathrm{N}_{\mathrm{f}} \quad \text { for } 0<\mathrm{R}<1
$$

\section{3 Experimental Modal Analysis}

The experimental setup was designed to measure damping loss factor using modal analysis [12-13] on specimens with overall dimensions shown in Fig.l Specimens were freely supported to avoid the effect of the ground support device on the obtained results, as shown in Fig.2.

A piezoelectric transducer for impact hammer was used for excitation, and a similar transducer for acceleration measurements was mounted in the same position with ( 2.2 gram) to assure that no additional mass for sensor could affect the results. The actuator/sensor position has been chosen such that a sufficient amount of energy introduction into the structure and a sufficient high output signal is generated in the sensor element. This is very useful for resonance dwell parameters since individual mode could be precisely exciting without exciting other modes. The measurements were made at each natural frequency as shown in Fig.3.

From Fig.3, a linear relationship between the response acceleration and excitation force in full frequency range exists. The observed drops in coherence at low frequency are explained from the expected behavior of the suspension.

In Fig.4 the modal damping $\left(\eta_{\mathrm{i}}\right)$ is computed from frequency response function (FRF) at a selected resonance in the range of investigated modes using curve fitting for multiple measurements around resonance frequency. The sensitivity to experimental error is reduced using coherence function.

The number of available eigen frequencies for comparison between experimental tests and analysis is limited for the suitability of the individual measured resonance for curve fitting (frequency spacing and peak height).

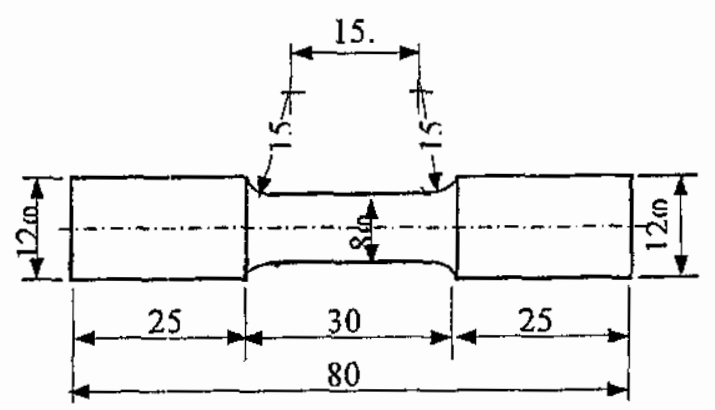

Fig. 1 Fatigue test specimen (dim. in $\mathrm{mm}$ )

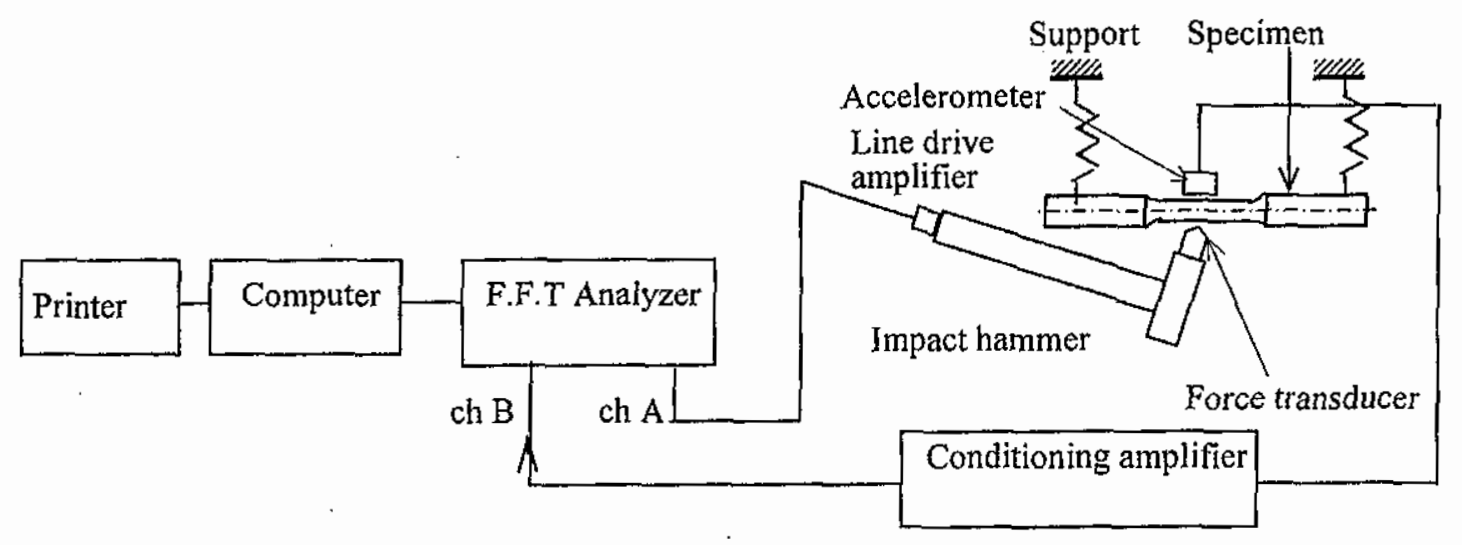

Fig.2 Set-up for vibration test 


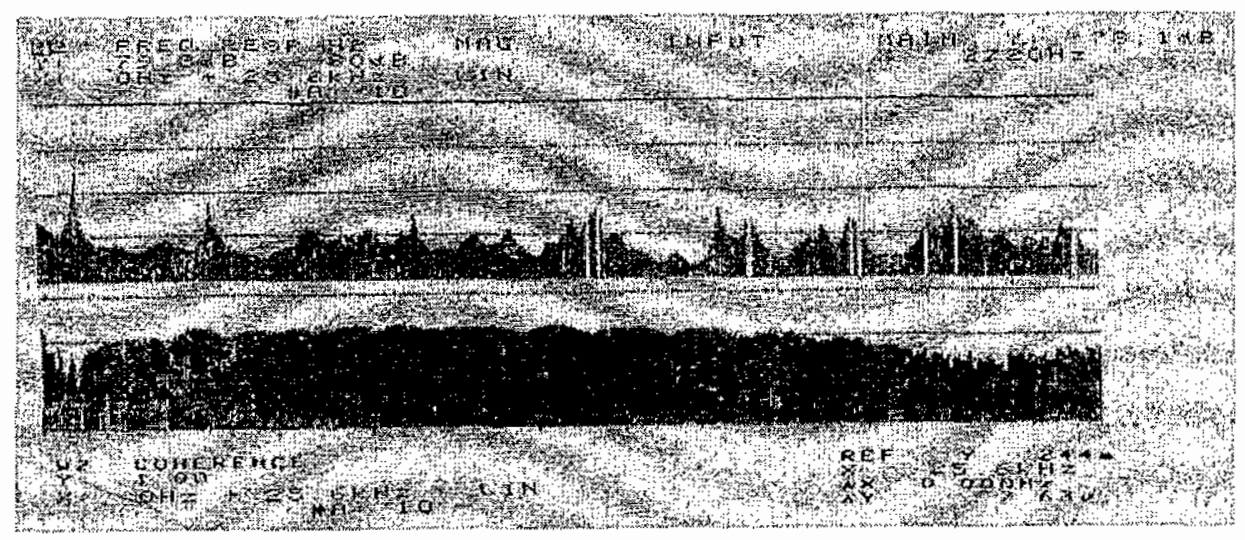

Fig.3 A sample of measured frequency response function together with coherence function

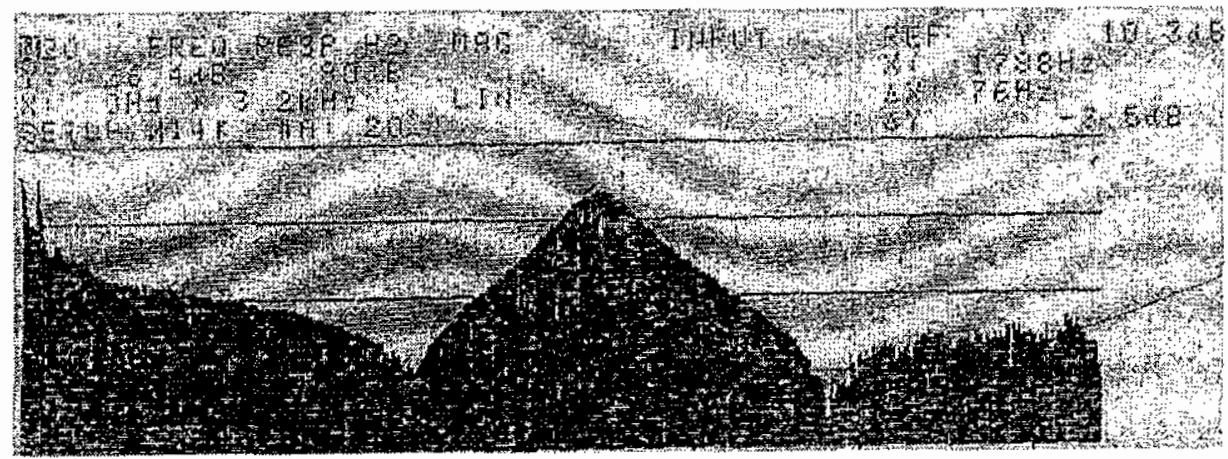

Fig.4 Zoom for selected mode

Beside the nonlinearity behavior of the suspension at low frequency, as shown Fig.3, and anti-resonance represents frequencies at which the structure does not respond to the excitation giving a poor signal to noise ratio. Therefore, four sets of modes have been selected to investigate the analytical modes chosen for correlation, these modes were $\left(2^{n d}, 3^{\text {rd }}, 5^{\text {th }}\right.$ and $\left.7^{\text {th }}\right)$. The values of these modes a given in Table 3 .

The experimental and analytical damping factor deviators were correlated through the modified assurance criteria MAC [11]. The MAC values were close to 0.9 .

For the sake of verification, the measured natural frequencies and damping loss factor before fatigue test $(\mathrm{R}=0)$ are extracted from Figs 3,4 and listed in the table below.

Table 3 the experimental parameters $\left(\omega_{i}\right)$ and $\left(\eta_{i}\right)$ of free-free specimen before fatigue test.

\begin{tabular}{|c|c|c|}
\hline \multirow{2}{*}{ Mode No. } & \multicolumn{2}{|c|}{ Experimental } \\
\cline { 2 - 3 } & $\boldsymbol{\omega}_{\mathrm{i}(\mathrm{Hz})}$ & $\boldsymbol{\eta}_{\mathrm{i}(\%)}$ \\
\hline 2 & 4572 & 0.92 \\
\hline 3 & 12600 & 0.76 \\
\hline 5 & 20980 & 0.66 \\
\hline 7 & 23960 & 0.50 \\
\hline
\end{tabular}

The results of the available measurements were in good agreement with those obtained by numerical analysis given in Table.1. It is worth mentioning that specific characteristics of the experimental design is summarized and listed in Table 4.

Table 4.Summary of damping measurements

\begin{tabular}{|l|l|}
\hline Measurement system type & $\begin{array}{l}\text { Peak amplitude method } \\
\text { (resonance method) }\end{array}$ \\
\hline Damping term measured & $\begin{array}{l}\text { Damping Loss factor } \\
(\eta)\end{array}$ \\
\hline Direction modes & Flexure \\
\hline Oscillation mode & $2^{\text {nd }}, 3^{\text {rd }}, 5^{\text {th }}$, and $7^{\text {th }}$ \\
\hline Frequency range & $(2000 \mathrm{~Hz}-25 \mathrm{kHz})$ \\
\hline Driving force & Impact hammer \\
\hline Measurement device & $\begin{array}{l}\text { Piezoelectric } \\
\text { Accelerometer }\end{array}$ \\
\hline Temperature & Room temperature \\
\hline
\end{tabular}

The measured damping loss factors obtained from frequency response data of fatigue tests before and after specific fatigue life ratios, are shown in Table 5.and drawn in Fig.11a. 
Table 5.Experimental modal damping $\left(\eta_{\mathrm{i}}\right)$ of free-free specimen for different ratios of fatigue cycle $(R)$ before heat treatment (as received specimens).

\begin{tabular}{|c|c|c|c|c|c|}
\hline \multirow{2}{*}{$\begin{array}{l}\text { Mode } \\
\text { No. }\end{array}$} & \multicolumn{5}{|c|}{ Damping loss factor $(7 ; \%)$} \\
\cline { 2 - 6 } $\mathbf{R}$ & $\mathbf{0}$ & $\mathbf{0 . 2}$ & $\mathbf{0 . 4}$ & $\mathbf{0 . 6}$ & $\mathbf{0 . 8}$ \\
\hline 2 & 0.92 & 0.91 & 0.60 & 0.5 & 0.43 \\
\hline 3 & 0.76 & 0.75 & 0.55 & 0.42 & 0.39 \\
\hline 5 & 0.66 & 0.65 & 0.50 & 0.39 & 0.36 \\
\hline 7 & 0.50 & 0.48 & 0.40 & 0.32 & 0.27 \\
\hline
\end{tabular}

The experimental damping loss factors $\left(\eta_{i}\right)$ are measured for different fatigue life ratios (R) and for quenched and peak-aged state and the results are listed in table (6) and table (7) respectively.

Table.6 Experimental modal damping loss factor $\left(\eta_{i}\right)$ as-quenched specimens

\begin{tabular}{|c|c|c|c|c|c|}
\hline $\begin{array}{c}\text { Mode } \\
\text { N0. }\end{array}$ & \multicolumn{5}{|c|}{ Damping loss factor $\left(n_{\mathbf{i}} \%\right)$} \\
\cline { 2 - 6 } $\mathbf{R}$ & $\mathbf{0}$ & $\mathbf{0 . 2}$ & $\mathbf{0 . 4}$ & $\mathbf{0 . 6}$ & $\mathbf{0 . 8}$ \\
\hline 2 & 0.98 & 0.98 & 0.82 & 0.80 & 0.70 \\
\hline 3 & 0.96 & 0.90 & 0.75 & 0.70 & 0.66 \\
\hline 5 & 0.86 & 0.80 & 0.69 & 0.62 & 0.60 \\
\hline 7 & 0.79 & 0.77 & 0.59 & 0.56 & 0.51 \\
\hline
\end{tabular}

Table. 7 Experimental modal damping loss factor $\left(\eta_{i}\right)$ as-peak-aged specimens

\begin{tabular}{|c|c|c|c|c|c|}
\hline Mode & \multicolumn{5}{|c|}{ Damping loss factor $\left(\boldsymbol{\eta}_{1 \%}\right)$} \\
\hline No. & \multicolumn{6}{|c|}{$\mathbf{R}$} & $\mathbf{0}$ & $\mathbf{0 . 2}$ & $\mathbf{0 . 4}$ & $\mathbf{0 . 6}$ & $\mathbf{0 . 8}$ \\
\hline 2 & 0.98 & 2.2 & 1.9 & 1.6 & 1.4 \\
\hline 3 & 0.96 & 1.9 & 1.6 & 1.5 & 1.2 \\
\hline 5 & 0.86 & 1.6 & 1.3 & 1.2 & 0.9 \\
\hline 7 & 0.77 & 1.4 & 1.1 & 1.0 & 0.7 \\
\hline
\end{tabular}

The measured natural frequencies at different fatigue life ratios are listed in Table 8.

Table .8 Experimental natural frequencies of freefree specimens at different fatigue ratios $(R)$.

\begin{tabular}{|c|c|c|c|c|}
\hline \multirow{2}{*}{$\begin{array}{l}\text { Fatigue } \\
\text { ratio } \\
\text { Thode } \\
\text { No. }\end{array}$} & \multicolumn{4}{|c|}{ Natural frequencies $\left(\omega_{i}\right)$} \\
\hline & $2^{n d}$ & $3^{\text {rd }}$ & $5^{\text {th }}$ & $7^{\text {th }}$ \\
\hline 0.0 & 4572 & 12600 & 20980 & 23960 \\
\hline 0.2 & 4573 & 12601 & 20980 & 23960 \\
\hline 0.4 & 4572 & 12600 & 20981 & 23960 \\
\hline 0.6 & 4575 & 12603 & 20982 & 23962 \\
\hline 0.8 & 4576 & 12607 & 20986 & 23963 \\
\hline
\end{tabular}

\section{ANALYSIS AND DISCUSSION}

\subsection{Aging behavior}

During aging, the solid solution elements $(\mathrm{Mg}, \mathrm{Si}$, $\mathrm{Cu}$ ) in the supersaturated solution began to precipitate. The higher the aging temperature the higher the nucleation sites for precipitates will be [14]. This will facilitate the attainment of peak hardness at much shorter times, Fig.5. The hardness of the materials increased as the number of the precipitates increased. After the hardness reached a maximum value (the peak aging condition) further aging led to the coarsening of the precipitates and softening resulted. An alternate pheneomenon which tended to occur during isothermal aging was annihilahion of dislocations that were unstable at higher temperature.

Detailed precipitation sequence for the 6061 aluminium alloy has been studied by Dutta and Allen [15]. The followings aging sequence for 6061 aluminum alloy was indicated: Supersaturated solid solution clusters of solute atoms and vacancies (premitive Guinier-Preston \{GP\} zone) - needleshaped G Pzone-rod-shaped,metastable, hexagonal, semicoherent $\beta$ 'phasestable, incoherent, cubic, $\mathrm{Mg}_{2} \mathrm{Si}$ precipitate ( $\beta$ phase).

Regardless of the nature of the precipitates, for needle distribution of the alloying constituents, aging in the 6061 aluminium alloys always involves the diffusion of $\mathrm{Mg}$ and $\mathrm{Si}$ atoms in the aluminium alloy, i.e. the process is diffusion controlled.

As the aging time and temperature increase, the density of $\mathrm{GP}$ zones will also increase (i.e. form coherent precipitates $\mathrm{Mg}_{2} \mathrm{Si}$ ). Hence, the degree of irregularity in the lattices will cause an increase in hardness. A reduction in hardness of the alloy in the over-aging conditions (increase in aging time and temperature) has occurred because of coalescence of the precipitates into larger particles, bigger grain size and the formation of non-coherence precipitates of microscopic sjze.

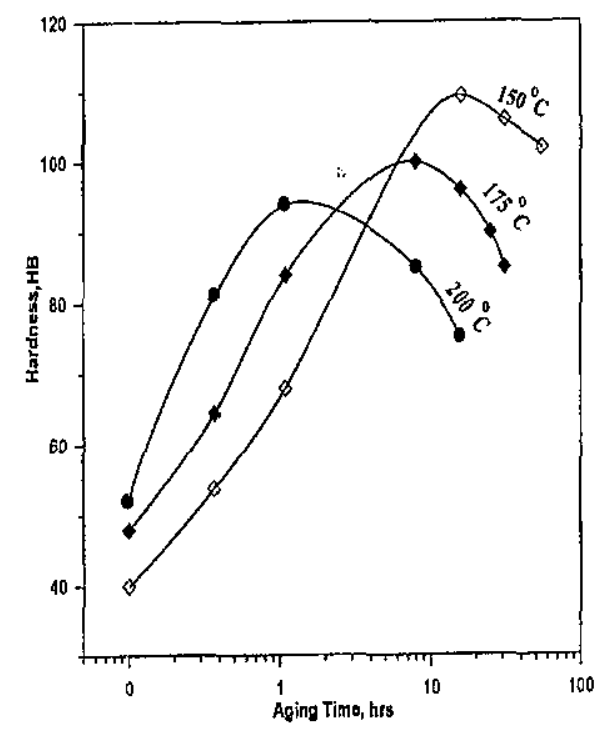

Fig. 5 Variation of hardness with time of aging, solution- treated at $550^{\circ} \mathrm{C}$ for $2 \mathrm{~h}$ 
Figure 6. shows X-ray photography of the HIP'ed sample which revealed defect-free fully dense structure. A density of $2.693 \mathrm{~g} / \mathrm{cm}^{3}$ was measured for HIP`ed samples and was attributed to the increased densification and thus increased bonding between powder particles.

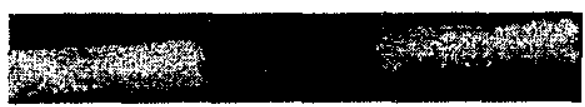

Fig. 6 X-ray picture of specimen

Microsturctural obeservations of HIP'ed materials are shown in Fig.7 for quenched and peak-aged conditions. The peak-aged specimence revealed precipitates of $\mathrm{Mg}_{2} \mathrm{Si}$ as small dots. Thermal vacancies introduced during the cooling cycle of the HIP treatment may simulate the prcipitation.
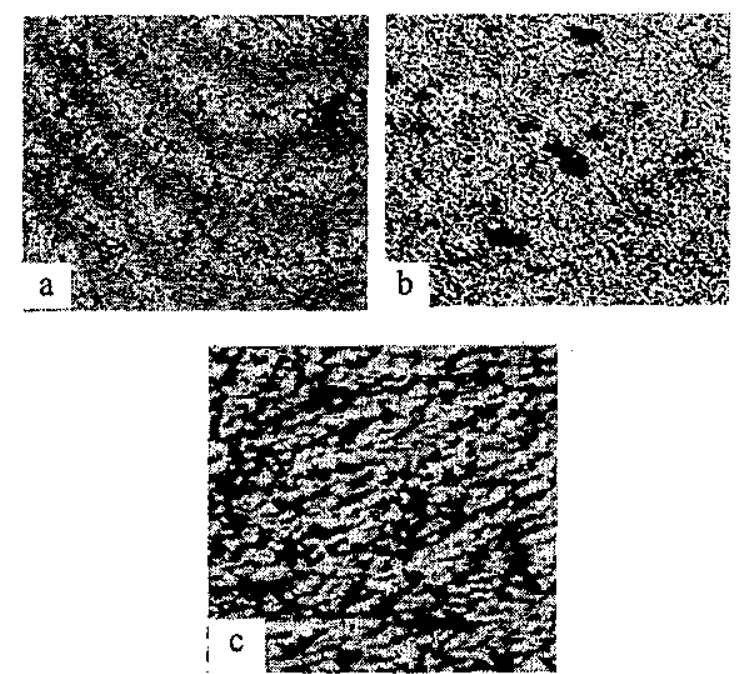

Fig.7 Structure of Hipped specimenes, a) as quenched $200 \mathrm{x}$, b) peak aged $600 \mathrm{x}$ ( light microscope) and c) peak-aged (SEM) 1000x

\subsection{Fatigue behavior}

The effect of processing on HIP'ped materials on S$\mathrm{N}$ curve and conventional powder technique Ref.[16] plotted in Fig. 8 for comparison with present results. Because aluminium and most of its alloys present continuously decreasing fatigue strength with an increasing number of cycles, the fatigue limit is defined as the fatigue strength at $10^{7}$ cycles. As a result, the fatigue strengths are 50,100 and $115 \mathrm{Mpa}$ for conventional, HIP, and aged alloy, respectively. As can be observed from fatigue curves, the peakaged specimens have the highest fatigue strength compared with the conventional material with an increase of $130 \%$ due to dense, defect-free structure and by $15 \%$ than the HIP'ed materials.
In case of age hardening, the strength of the matrix is increased by the action of submicroscopic particles $\left(\mathrm{Mg}_{2} \mathrm{Si}\right)$ in impeding the movement of "dislocation front". Since, such dislocations pass through such particles because they are harder and stronger than the matrix; "loops" are formed. This dislocation loops act as further barriers to the progress of any dislocation front, which may follow. Furthermore, in the heat treatable aluminium alloy, work hardening induced by fatigue deformation, not only supplement the strength achieved by precipitation hardening, but also increase the rate of precipitation hardening. This treatmeant increases the strength in at least two ways. Firstly, it gives the finer precipitate by introducing more dislocations as nucleate sites. Secondly, the high density of dislocations resulting from fatigue deformation are subsequently trapped in place by precipitation giving a relatively rigid tangle of dislocations through which additional dislocations must be forced through for further deformation to occur. The introduced dislocations and point defects increase the internal strain energy and provide the driving force for the microstructural changes that occur during aging.

Also, the increase in fatigue strength of peak-aged alloy can be partially attributed to the dynamic strain aging effect that will enhance additional precipitation in finer forms. This effect surpasses the softening due to dislocation annihilation. The nucleation mechanism of precipitates during dynamic aging is proved to be dislocation-assisted process. Meanwhile, coarsening of the precipitates in the 6061 alloy may be due to dislocation acting as short-circuit diffusion path for solute during dynamic aging [17].

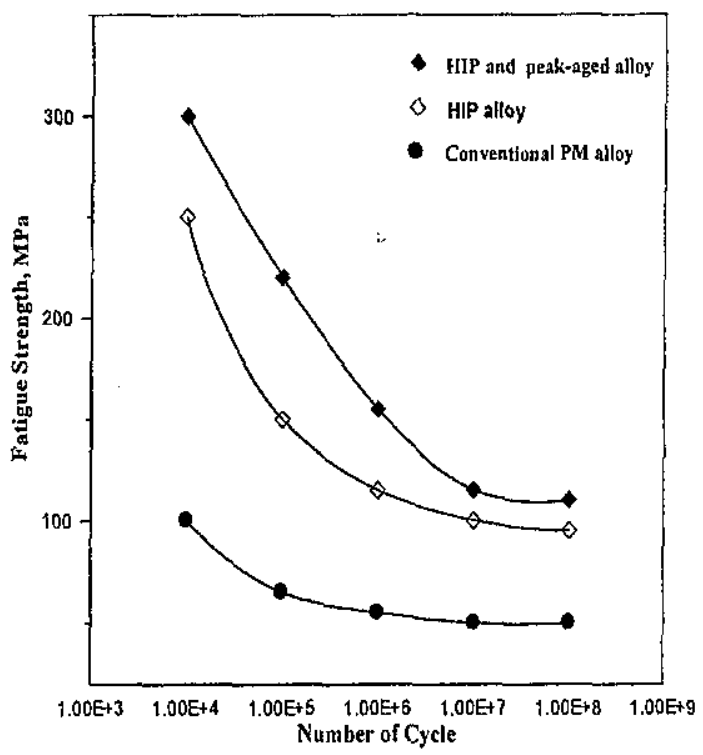

Fig.8 Effect of processing on S-N curves 


\subsection{Fractography}

Fractographic analysis of fatigue failed specimens, in Figs. 9 and 10 have shown the operation of several modes of fracture depending on the type of heat treatment and so the microstructural parameters. However, an examination of the fracture surface of peak-aged sample revealed the classical, dimple ductile surface, Fig.10-a. In such case, fracture proceeds by nucleation, growth and coalescence of voids. The voids then grow under fatigue loading and influence the local plastic constraint until a coalescence mechanism is activated, followed by the total failure of the specimen.

The morphology of the fracture surface for the asreceived samples was similar to that for the peekaged but larger dimples were observed, Fig10.b.

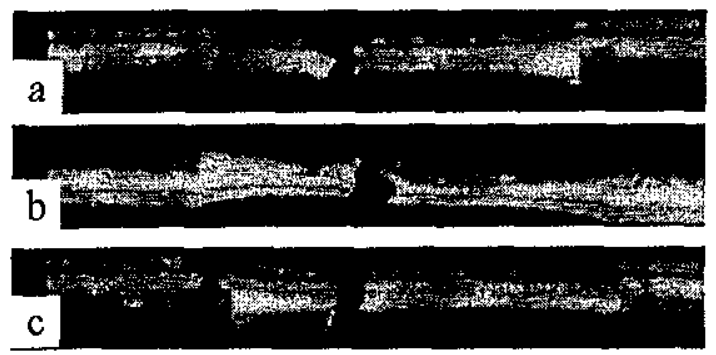

Fig.9 Fatigue fracture morphology of, a) Peakaged , b)As-received ,andc)As-quenched
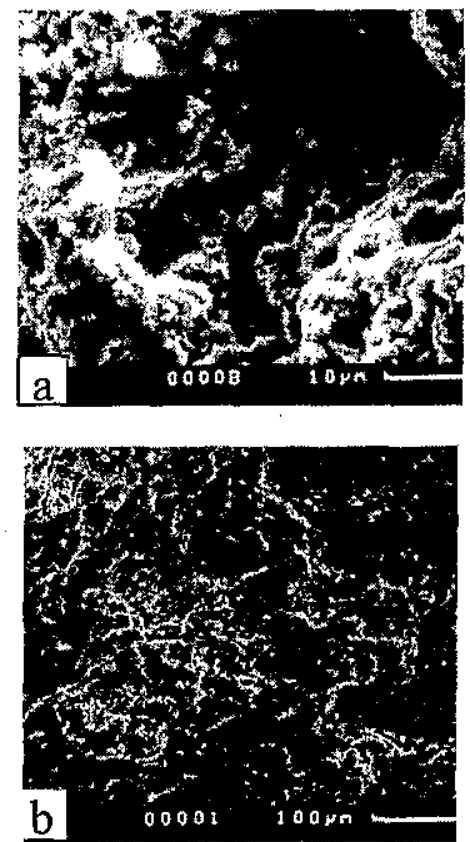

Fig.10 SEM of fracture surface of a) Peak-aged and b) As-received

\subsection{Modal damping loss factor behavior}

Fig.11 $(a, b$, and $c)$ reports the measured values of damping loss factor $(\eta)$ for specimens, in as-received, as-quenched and as peak-aged versus the by fatigue life ratios for each mode of vibration. It is evident from the figure that damping loss factor of specimen depends not only on the modes (resonant frequency), but also on fatigue life ratio, within the range of resonant frequencies $(2000 \mathrm{~Hz}-25 \mathrm{kHz})$.

With the help of fitting techniques the relationship between the experimental results of damping loss factors and fatigue life ratios are deduced and given as

$$
\eta_{i}=a(R)^{\gamma} \quad \text { for } 0<R \leq 1
$$

where, a, $\gamma$ are weight factors depending on the materials properties and number of cycles.

The fitting plots of measured values are plotted within the range of confidence level equal to $97.96 \%$ to $99.69 \%$. The highest damping loss factor was found to be 0.022 for the aged specimen compared with the Hip'ed or even quenched specimens.

The increases in damping loss factor for the peakaged samples can be explained as follows: among the known damping mechanisms, dislocation damping is one of the most important in aluminium. An increase in dislocation damping means an increase in dislocation mobility and consequently a decrease in mechanical strength. A good combination of the mechanical properties and of the damping capacity could be achieved if the dislocation loops, which on one hand are firmly pinned by precipitates. On the other hand when allowed to vibrate between these pinning points, dislocation damping is proportional to the dislocation density and to the square of the mean dislocation loop length [18]. In aluminium alloys, the strengthening is typically obtained by precipitation. In order to improve the damping, it is necessary to lower the concentration of foreign atoms, which remain in solution to increase the dislocation loop length and consequently the dislocation local mobility.

Quenching increases the damping loss factor by $7 \%$, $28 \%, 33 \%$, and $54 \%$ for associated modes respectively, compared with the as-receive specimens; however, aging increases the damping loss factor by $160 \%$ at $R=0.2$.

The precipitation transformation on aging will induce the depletion of solute atoms in matrix and simultaneously the formation of coherent and incoherent precipitate. Generally, the coherent precipitate has a role of stronger pining effect than the point defect source [19]. 

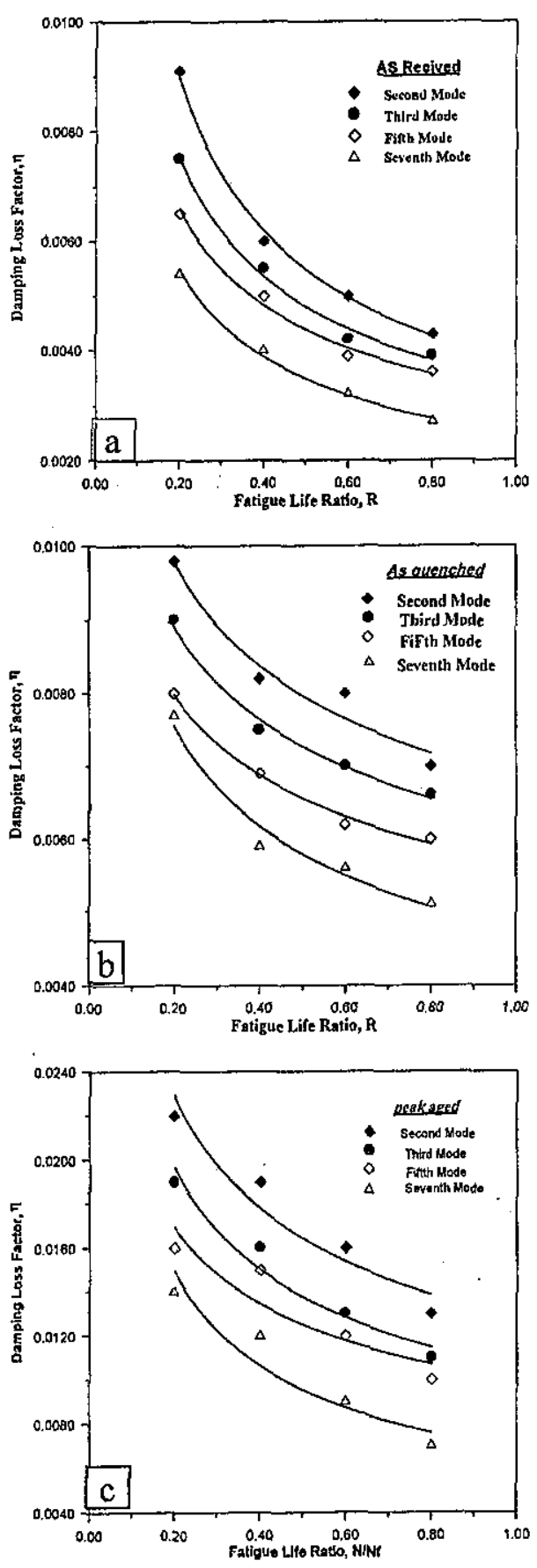

Fig.11. Variation of damping loss factors with fatigue life ratio ( $R$ ) for the different modes a) as received, $b$ ) as quenched and c) peak-aged at stress $120 \mathrm{MPa}$.

This has favorable effect of coherent- strong pinning point on damping capacity as reported by $\mathrm{Li}$ et al .[2]. It was reported in their recent study that the damping capacity of rapid solidification and powder metallurgy (RS-PM) Al-Fe-Mo-Si alloy is remarkably enhanced by precipitation of $\mathrm{Al}_{12}(\mathrm{Fe}$, $\mathrm{Mo})_{3} \mathrm{Si}$ dispersions. Since the strong pining point such as $\mathrm{Mg}_{2} \mathrm{Si}$ has more powerful effect than the weak pinning point for strain independent range, the damping loss factor of peak-aged specimen will be increased through the formation of strong pinning effect with depletion of solute concentration in the matrix.

Therefore, from the viewpoint of dislocation damping mechanism, the enhancement of the damping loss factor can be achieved through the control of pinning effect between solute atom and dislocations, without degradation of mechanical property.

In the area of dynamic environment, it is important to take into account the influence of inertia distribution. The dependence of damping loss factor on frequency, as depicted in Fig.12. The relation follows the hyperbolic form with quasiuniform mass damping as defined by the ratio $\alpha_{m} / \omega_{i}$ in equation (11) and as given in [20]. The figure can be classified into two regions depending upon the change of the frequency. The first is the low frequency range (up to 12600 $\mathrm{Hz}$ ), and the second is the high frequency range $(12600$ to $23960 \mathrm{~Hz})$. In the high frequency range, the effect of frequency on loss factor damping diminishes. Whereas on the low frequency range, the higher the frequency the lower the damping. Similar results were found for steel alloy [21]. However, no explanation from these experimental findings was offered in previous work. The decrease in damping with frequency as depicted in Fig. 12 can be attenuated by the Granato-Lucke theory [22].

The dislocation damping depends fundamentally upon the dislocation density since the sweeping motion of dislocation to pinning point induces energy dissipation that is proportional to the traversed area by dislocation movement.

Besides, the distance between pinning points influences also the dislocation mobility. The latter is also related to the number and source of pinning point, temperature, and diffusivity of pinning point as was stated by Lee [23]. Therefore, the experimental results shown in Fig. 12 can be interpreted on the viewpoint of both dislocation damping and interfacial damping mechanism. So it is expected that the decrease of both interfacial boundary layer and dislocation mobility results in decrease in damping loss factor with frequency. However, the understanding of the individual contribution on damping loss factor was beyond the scope of the present study and further details are required.

To facilitate the quantitative analysis of the weight factors (a and $\gamma$ ) for updating mathematical modal, logarithmic relation between the damping loss factor $(\eta)$ and the fatigue life ratio (R) for different modes are plotted in linear form as shown in Fig. 13 a, b, 
and $c$ at the selected resonant frequency. The applications of extrapolation and interpolation techniques are useful for controlling the damping loss factor and number of cycles at the selected resonant frequency and at any fatigue life ratios.

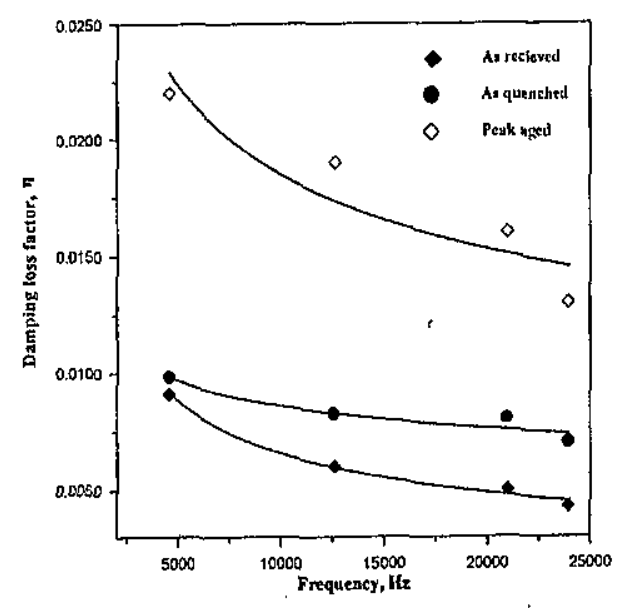

Fig.12 Variation of damping loss factors with frequency $(\mathrm{Hz})$ for the materials at stress 120 $\mathrm{MPa}$ and fatigue life ratio 0.2 .

Consequently, the damage modes, which represent the relation between the damping loss factor $(\eta)$ at the failure $(\mathrm{R}=1)$ and resonant frequencies are deduced and plotted in Fig.14. The figure helps in detecting the damage caused by fatigue cycling damage mode as described by a reduction in ( $\eta$ ) as the frequency changes from mode to mode. The experimental results shown in Fig. 14 could be a useful guide for preventing fatigue damage or even predicting the remaining life through measuring the

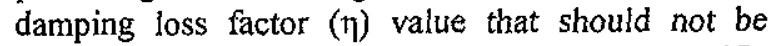
lower than that given by the curve for a specific structure and resonant frequency.

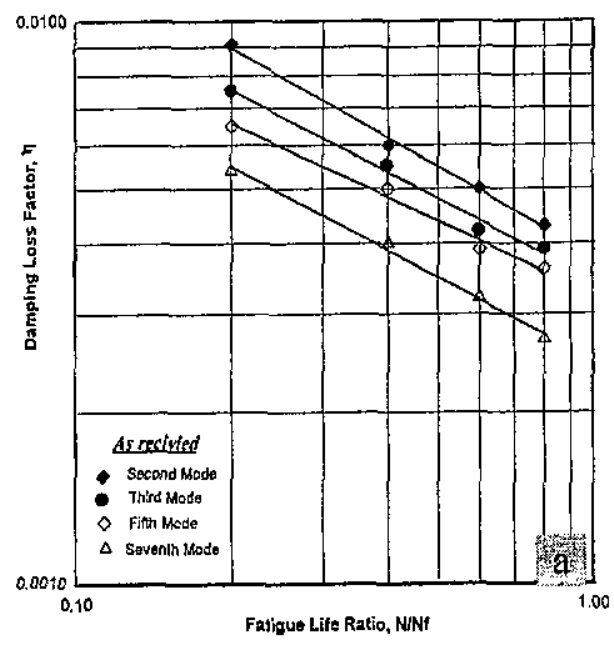

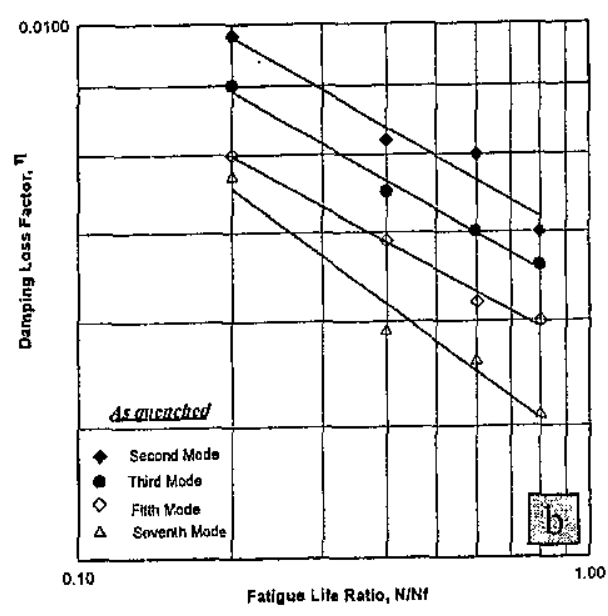

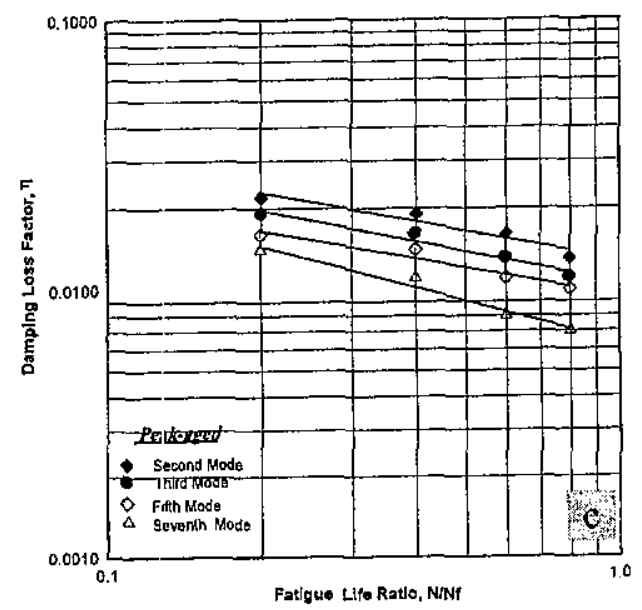

Fig.13 a, b, c Logarithmic representation of damping loss factor and fatigue life ratio for various structures and modes of frequencies

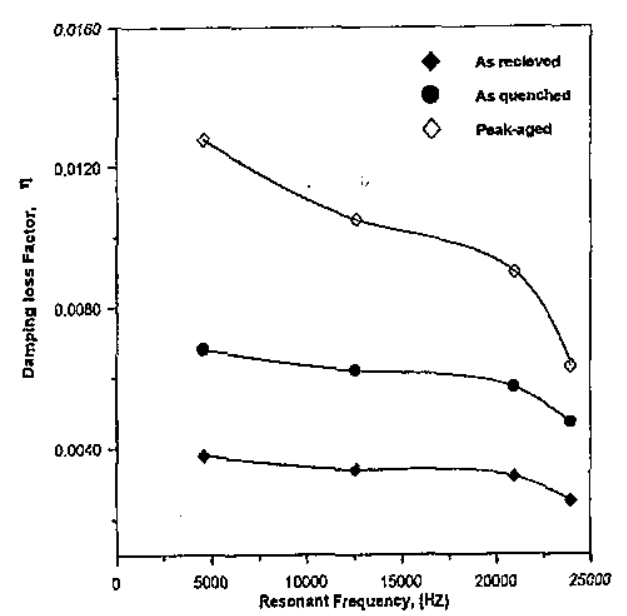

Fig. 14 Dependence of damping loss factor at fatigue failure $(R=1)$ on resonant frequency for various conditions. 


\section{CONCLUSIONS}

In view of the analysis of the results in the present work, one can conclude:

1- A hyperbolic relation between damping loss factor $(\eta)$ and fatigue life ratio (R) are deduced. This relation provides efficient tool for predicting the fatigue damage behavior.

2. In contrast to the considerable change in the measured damping loss factors, the associated measured frequencies are invariant for various fatigue ratios $(R)$.

3. The quantitative analysis and applications of extrapolation and interpolation techniques utilized in the present work are good to control the damping loss factor and fatigue life at the selected resonant frequency.

4. The experimental analysis shows that 6061 aluminium alloy having the highest damping in the peak-aged condition. So, in order to obtain high damping without degradation of fatigue strength, it is preferred to lower the concentration of foreign atoms which remain in solution. Careful control of alloy preparation and processing are of great importance. Hot isostatic pressing technique offers a uniform, defect-free structure with improved quality.

Finally it is recommended for a future work to examine the effect of test temperature on modal damping variation. Also, the predictability of the proposed formula for fatigue life estimation on composite structure will be of great interest.

\section{REFERENCES}

[1] R.Sadeler, Y.Totik, M.Gavagah, I.Kaymaz "Improvements of Fatigue Behavior in $2014 \mathrm{Al}$ alloy by Solution Heat Treating and AgeHardening", Materials and Design, 25, 2004, pp 439-445.

[2] P.Y.Li, H.J. Yu, S.C.Chai, Y.R.Li "Microstructure and Properties of Rapidly Solidified Powder Metallurgy Al-Fe-Mo-Si alloy", Scripta Materialia, 49, 2003, pp 819824.

[3] P.Y.Li, S.L.Dai, S.C.Chai, Y.R.Li "High Damping Al-Fe-Mo-Si/Zn-Al Composites Produced by Rapidly Solidified Powder Metallurgy", Scripta Materialia, 42, 2000, pp 955-960.

[4] A.N.Damir, A.Elkhatib, G.Nassef,"Effect of Microstructure on Dynamic Characteristics and Fatigue Behavior of Austempered Ductile Iron", 8th International Conference on Production Engineering Design and Control, PEDAC, December 2004, Alexandria, Egypt.
[5] A.N.Damir, A.Elkhatib, G.Nassef,'Prediction of Fatigue Life Using Modal Analysis", $8^{\text {th }}$ International Conference on Production Engineering Design and Control, PEDAC, December 2004, Alexandria, Egypt.

[6] G.M.Song, T.S.Lui, J.H.Horng, L.H Chen, T.F.Chen, "Vibration Behavior of a PrecipitationHardening Aluminum Alloy under Resonance", Scripta Materialia, 51, 2004, pp 1153-1157.

[7] S.W Doebling, C.R.Farrar and M.B.Prime", A Summary Review of Vibration-Based Damage Identification Method", Shock and vibration digest, 30, 1998, pp 91-105.

[8] S.Deobling, C.Farrar, M.Prime, D.Shevitz," Damage identification and health monitoring of structural and mechanical systems from change in their vibration characteristics: A literature review", Loss Alamos National laboratory Report, La-Ms-1996, 1307.

[9] M.I. Friswell, J.E.T Penny and D.A.L.Wilson", Using Vibration Data and Statistical Measures to Locate Damage in Structure", Journal of Analytical and Experimental Modal Analysis, 9, 1994, pp239-254.

[10] Ivan C. Davis," Damage Detection in Aluminum Cylinder Using Modal Analysis", MSc Thesis, Department of Mechanical Engineering, Virginia Polytechnic Institute and State university,2002

[11] Grzegorz Kawieeki, "Modal damping measurements for damage detection maintenance and reliability conference, Tennesse, May, 5-8, 2001.

[12] Brain J.Schwarz, Mark H. Richardson," Experimental Modal Analysis", CSI Reliability Week, Orlando, Fl, 1999.

[13] A. Riviere, "Measurement of High Damping: Techniques and Analysis", Journal of Alloys and Components, 355, 2003, pp 201-206.

[14] Hsu-Shen Chu, Kuo-Shung Lig Liu, and JienWei Yeh"Study of 6061- $\mathrm{Al}_{2} \mathrm{O}_{3}$ Composites Produced by Reciprocating Extrusion", Metallurgical and Materials Transactions A, $31 \mathrm{~A}, 2000$, pp 2587-2596.

[15] I. Dutta and S.M. Allen," A Calorimetric Study of Precipitation in Commercial Al alloys 6061" J.Matterial. SiC. Lett.10, 1991, pp323-326.

[16] J.R. Davis, ASM Specialty Handbook" Aluminum and Aluminum Alloys", 1994

[17] M.Cai, D.P. Field, G.W Lorimer, "A systematic Comparison of Static and Dynamic Ageing of Two Al-Mg-Si Alloys", Materials Science and Engineering, A373, 2004 , pp 65-71. 
[18] C.Y.Yie, R.Schaller, C.Jaquerod,"High Damping Capacity after Precipitation in Some Commercial Aluminum Alloys", Materials Science and engineering, A252, 1998, pp 78-84.

[19] O.A. Lambri, W, Riehemam, "Damping due to Incoherent Precipitates in Commercial Q E22 Magnesium Alloy", Scripta Materialia, 52, 2005, pp 93-97.

[20] A.Maher, "Evaluative Eigen Analysis of Composite Structure", Composite Structure, 29, 1994, pp 191-195.
[21] A. Tandl, "Some Problems of Rotor Dynamics", Champanond Hell, 1965.

[22] A. Granato, K.Lucke,"Recovery of Damping and Modulus Changes Following Plastic Deformation", July, 1958, pp 470-480.

[23] Choong Do Lee," Damping Properties on Age Hardening of Al-7Si $0.3 \mathrm{Mg}$ Alloy During T6 Treatment", Materials Science and Engineering, A394, 2005, pp 112-116. 